\title{
Microbiological Quality Assessment of Vitamin B Syrups and Antibiotic Susceptibility Profile of the Isolated Escherichia coli
}

\author{
Md. Shahinur Kabir ${ }^{1}$ and Mohammad Dulal Hossain ${ }^{2}$ \\ ${ }^{I}$ Department of Botany, Jahangirnagar University, Savar, Dhaka, Bangladesh \\ ${ }^{2}$ Department of Microbiology, Primeasia University, Banani, Dhaka, Bangladesh.
}

\begin{abstract}
The microbiological quality of 15 different vitamin B syrup samples of 7 pharmaceutical companies was assessed. The total aerobic microbial count (TAMC) varied between $1.0 \times 10^{l} \mathrm{CFU} / \mathrm{ml}$ and $6.0 \times 10^{3} \mathrm{CFU} / \mathrm{ml}$. The total yeast and mold count (TYMC) ranged from $1.0 \times 10^{1} \mathrm{CFU} / \mathrm{ml}$ to $5.3 \times 10^{2} \mathrm{CFU} / \mathrm{ml}$. In general, all the samples tested were contaminated with microorganisms. Our findings revealed that 10 (66.67\%) out of the 15 samples exceeded the microbiological acceptance limit of USP. Moreover, presence of Escherichia coli was detected in 2 samples. The E. coli isolates were subjected to antibiotic susceptibility test against 7 antibiotics. All the E. coli isolates showed resistance against ampicillin and $2(33.33 \%)$ of the isolates showed resistance against cefaclor. None of the isolates demonstrated resistance against ciprofloxacin, kanamycin, meropenem, streptomycin and tetracycline. Presence of antibiotic resistant bacteria in pharmaceutical products is very alarming for the consumer. The presence of high level of microbial contamination highlighted the need to reevaluate the production process of the pharmaceutical companies involved in production of non-sterile products and take necessary steps to prevent microbial contamination.
\end{abstract}

Key words: Antibiotic resistance, Microbial contamination, Non-sterile pharmaceutical product, Vitamin.

\section{Introduction}

The microbial quality of pharmaceutical products primarily depends on the quality of raw materials, production process, production environment, hygiene of the personnel involved in manufacture and the storage conditions. Not only the presence of pathogenic microorganisms but the presence of relatively high number nonpathogenic microorganisms is also objectionable in pharmaceutical products. The presence of high number of non-pathogenic microorganisms in pharmaceutical products is objectionable for two reasons: firstly, these microorganisms can deteriorate active ingredients and can interfere with the desired activity of the product; and secondly, they can produce some metabolites that may be toxic to the consumer [1].

Vitamins are a group of organic nutrients, required in small quantities for a variety of biochemical functions that, generally, cannot be synthesized by the body and must therefore be supplied in the diet [2]. The vitamin $\mathrm{B}$ complex, one of the water soluble vitamins, is actually a group of 8 (thiamin, riboflavin, niacin or niacinamide or nicotinic acid, pyridoxine or pyridoxamine or pyridoxal, folic acid, cobalamin, pantothenic acid and biotin) vitamins. The members of the vitamin B complex play very important role in various metabolic activities including metabolism of carbohydrates, proteins and fats. Deficiency of the members of vitamin B complex results various symptoms in the human body. For example, thiamin deficiency causes beriberi; riboflavin deficiency results cheilosis, glossits and seborrhea; niacin deficiency causes pellagra; cobalmin deficiency results pernicious anemia, folic acid deficiency leads to megaloblastic anemia, etc. [2]. Vitamin B syrups are aqueous preparations for oral use and usually marketed in non-sterile dosage form.

Escherichia coli, a gram negative aerobic or facultative anaerobic bacterium, is a commensal of human gastrointestinal tract. Virulent strains of $E$. coli can cause several health problems including gastroenteritis, urinary tract infections, and neonatal meningitis. In rare cases, virulent strains are also responsible for hemolytic-uremic syndrome (HUS), peritonitis, mastitis, and septicemia. During the two decades, several outbreak of gastrointestinal illness have occurred by food borne pathogenic E. coli [3]. E. coli and other members of Enterobacteriaceae are important reservoirs of transferable antibiotic resistance [4]. Some strains of E. coli carry antibiotic resistant plasmids and readily transfer those plasmids to other species. So, the presence of antibiotic resistant $E$. coli is objectionable in food, water and medicine. In Bangladesh, some works were done on the microbiological quality of antacid suspension produced by pharmaceutical companies [5-7] but antibiotic resistance pattern of the isolates is not available. Here, we are presenting our findings on the microbiological quality of different brands of vitamin B complex syrups marketed in Bangladesh and antibiotic resistant profile of the isolated E. coli. 


\subsection{Sample collection}

\section{Materials and Methods}

Fifteen vitamin B complex syrups of 7 companies having different manufacturing date were collected from various retail pharmacy outlets in Dhaka, Bangladesh. For each of the samples, batch number, date of manufacture, date of expiry, dosage form was documented from the label attached to the bottle.

\subsection{Microbiological analyses}

Microbiological analyses included in this study were total aerobic microbial count (TAMC), total coliform count (TCC) and total yeast and mold count (TYMC). For enumeration of the microorganisms, vitamin samples were diluted in $0.9 \%$ normal saline. An aliquot from different dilutions were plated onto Nutrient agar (NA) for enumeration of TAMC, on MacConkey agar for TCC and on Sabouraud dextrose agar (SDA) for TYMC. The NA and MacConkey agar plates were incubated at $37{ }^{\circ} \mathrm{C}$ for $24-48 \mathrm{~h}$. The SDA plates were incubated at room temperature for 5 days. The characteristic colonies grown on the MacConkey agar plates were isolated and purified for morphological and biochemical study. On the basis of morphological, cultural and biochemical characteristics, 6 isolates were finally identified as E. coli [8-10].

\subsection{Antibiotic susceptibility test}

Susceptibility of the isolated E. coli to antibiotics was determined in vitro by employing disc diffusion method [11] and recommendations of Clinical and Laboratory Standard Institute [12]. Available antibiotic disc of ampicillin $(10 \mu \mathrm{g})$, cefaclor $(30 \mu \mathrm{g})$, ciprofloxacin $(5 \mu \mathrm{g})$, kanamycin $(30 \mu \mathrm{g})$, meropenem $(10 \mu \mathrm{g})$, streptomycin $(10 \mu \mathrm{g})$ and tetracycline $(30 \mu \mathrm{g})$ were used for the test. A portion of $E$. coli colony grown on nutrient agar medium was inoculated in nutrient broth and incubated at $37^{\circ} \mathrm{C}$ to obtain a young culture. A cotton swab was dipped in the suspension and the excess fluid was removed by pushing and rotating the cotton swab inside the wall of the tube just above the fluid level. Then the swab was streaked over the surface of MuellerHinton agar to obtain uniform inoculums. Antibiotic impregnated discs were then aseptically placed on the surface of the Mueller-Hinton agar medium with the help of sterile forcep. Each disc was gently pressed down onto the medium to ensure complete contact with agar surface. The plates were inverted and incubated at $37^{\circ} \mathrm{C}$. After 18-24 $\mathrm{h}$ incubation, the plates were examined and the diameter of the zones of inhibition was measured to the nearest whole millimeter. The $E$. coli isolates were classified as sensitive or resistant to a particular antibiotic based on the diameter of zone of inhibition.

\section{Results and Discussion}

The present study was carried out to reveal the microbiological quality of different brands of vitamin B complex syrups marketed in Dhaka, Bangladesh. All the samples were within their shelf-life at the time of investigation. All the products have their manufacturing and expiry dates stated. There was no leakage or crack on the bottles. The microbiological status of the vitamin B syrups examined in this study is presented in Table 1 .

Table 1: Microbial Load in the Vitamin B Complex Syrups

\begin{tabular}{|c|c|c|c|c|}
\hline \multirow[t]{2}{*}{ Brand Code } & \multirow{2}{*}{$\begin{array}{c}\text { Sample } \\
\text { Number }\end{array}$} & \multicolumn{3}{|c|}{ Microbial count $(\mathrm{CFU} / \mathrm{ml})$} \\
\hline & & TAMC & TCC & TYMC \\
\hline \multirow[t]{2}{*}{ A } & 1 & $1.0 \times 10^{1}$ & $\mathrm{ND}$ & $1.0 \times 10^{1}$ \\
\hline & 2 & $2.05 \times 10^{2}$ & $\mathrm{ND}$ & $1.0 \times 10^{1}$ \\
\hline \multirow[t]{2}{*}{ B } & 1 & $1.0 \times 10^{3}$ & ND & $3.5 \times 10^{2}$ \\
\hline & 2 & $3.3 \times 10^{2}$ & $1.0 \times 10^{1}$ & $1.0 \times 10^{1}$ \\
\hline \multirow[t]{2}{*}{$\mathrm{C}$} & 1 & $1.23 \times 10^{3}$ & ND & $1.0 \times 10^{1}$ \\
\hline & 2 & $5.1 \times 10^{2}$ & ND & $1.0 \times 10^{1}$ \\
\hline \multirow[t]{2}{*}{$\mathrm{D}$} & 1 & $6.0 \times 10^{3}$ & $1.0 \times 10^{2}$ & $5.3 \times 10^{2}$ \\
\hline & 2 & $3.0 \times 10^{1}$ & ND & $1.0 \times 10^{1}$ \\
\hline \multirow[t]{3}{*}{ E } & 1 & $3.0 \times 10^{1}$ & $\mathrm{ND}$ & $6.0 \times 10^{1}$ \\
\hline & 2 & $2.0 \times 10^{1}$ & ND & $7.0 \times 10^{1}$ \\
\hline & 3 & $1.0 \times 10^{2}$ & ND & $1.0 \times 10^{1}$ \\
\hline \multirow[t]{2}{*}{$\mathrm{F}$} & 1 & $5.5 \times 10^{1}$ & $\mathrm{ND}$ & $4.0 \times 10^{2}$ \\
\hline & 2 & $9.5 \times 10^{1}$ & ND & $1.0 \times 10^{1}$ \\
\hline \multirow[t]{2}{*}{$\bar{G}$} & 1 & $8.0 \times 10^{1}$ & $\mathrm{ND}$ & $1.0 \times 10^{1}$ \\
\hline & 2 & $1.35 \times 10^{3}$ & ND & $1.5 \times 10^{1}$ \\
\hline
\end{tabular}

CFU: colony forming unit; TAMC: Total aerobic microbial count; TCC: Total coliform count; TYMC: Total combined yeast and mold count; ND: Not detected.

The total aerobic microbial count (TAMC) varied between $1.0 \times 10^{1} \mathrm{CFU} / \mathrm{ml}$ and $6.0 \times 10^{3} \mathrm{CFU} / \mathrm{ml}$. Whereas, total yeast and mold count (TYMC) ranged between $1.0 \times 10^{1} \mathrm{CFU} / \mathrm{ml}$ and $5.3 \times 10^{2} \mathrm{CFU} / \mathrm{ml}$. Overall, 10 (66. $67 \%$ ) out of 15 samples exceeded the limit (TAMC $\leq 10^{2} \mathrm{CFU} / \mathrm{ml}$; TYMC $\leq 10^{1} \mathrm{CFU} / \mathrm{ml}$; and absence of $E$. coli) 
of United States Pharmacopeia [13]. Bacterial count more than $10^{3} \mathrm{CFU}$ per $\mathrm{ml}$ in syrup or suspension was also reported by several researchers [1, 5, 7]. Mugoyela and Mwambete [14] examined non-sterile pharmaceutical products in public hospital settings and reported the presence of heavy microbial contamination in $50 \%$ of the products. In a separate study only $5.5 \%$ of the vitamin samples were found contaminated with microorganisms [15]. Although, sterility is not a requirement in the official compendia for non-sterile pharmaceutical products, the microbial load of such product should be within the acceptable limit [14].

In this study, coliform bacteria were detected in two brands of vitamin B syrup (Table 1). Some of the colonies formed on the MacConkey agar plates were selected for further study. Based on standard morphological and biochemical tests, 6 of them were identified as Escherichia coli. Presence of coliform bacteria in two samples indicates that fecal contamination of the water might have occurred.

Antibiotic susceptibility test was carried out for the 6 selected $E$. coli isolates after being confirmed by morphological and biochemical tests. The diameter of zones of inhibition produced by the selected antibiotics against each of the isolates is presented in Table 2. It is evident that the isolates produces diverse type of zone of inhibition against the antibiotics tested.

Table 2: Zone of Inhibition of the $E$. coli Isolates $(\mathrm{n}=6)$

\begin{tabular}{|l|c|c|c|c|c|c|}
\hline \multirow{2}{*}{\multicolumn{1}{|c|}{ Antibiotic Disc }} & \multicolumn{5}{|c|}{ Zone of inhibition $(\mathrm{mm})$ of the selected isolates of E. coli } \\
\cline { 2 - 7 } & $\mathrm{EC}_{1}$ & $\mathrm{EC}_{2}$ & $\mathrm{EC}_{3}$ & $\mathrm{EC}_{4}$ & $\mathrm{EC}_{5}$ & $\mathrm{EC}_{6}$ \\
\hline Ampicillin $(10 \mu \mathrm{g})$ & 10 & 8 & 13 & 13 & 13 & 7 \\
\hline Cefaclor $(30 \mu \mathrm{g})$ & 13 & 20 & 14 & 15 & 20 & 18 \\
\hline Ciprofloxacin $(5 \mu \mathrm{g})$ & 25 & 25 & 22 & 17 & 29 & 25 \\
\hline Kanamycin $(30 \mu \mathrm{g})$ & 25 & 25 & 18 & 16 & 23 & 17 \\
\hline Meropenem $(10 \mu \mathrm{g})$ & 29 & 27 & 22 & 14 & 24 & 19 \\
\hline Streptomycin $(10 \mu \mathrm{g})$ & 14 & 25 & 15 & 13 & 22 & 20 \\
\hline Tetracycline $(30 \mu \mathrm{g})$ & 29 & 30 & 18 & 18 & 25 & 14 \\
\hline
\end{tabular}

$\mathrm{EC}_{1}$ to $\mathrm{EC}_{6}$ : Escherichia coli isolate.

Antibiotic resistance profile of the isolates is presented in Figure 1. All of the E. coli isolates were subjected to antibiotic susceptibility test and found resistant to ampicillin (Fig. 1). Resistance to ampicillin by $95 \%$ of the $E$. coli isolated from food was also reported by other research group [16]. It is alarming that 2 of the $E$. coli isolates are resistant to cefaclor. However, none of the E. coli isolates showed resistance against ciprofloxacin, kanamycin, meropenem, streptomycin and tetracycline (Fig. 1).In Bangladesh, there are several reports on the presence of antibiotic resistant Escherichia coli in natural, household and waste water [17,18, 19]. We speculate that the water used in the syrup preparation might be the source of antibiotic resistant $E$. coli observed in this study.

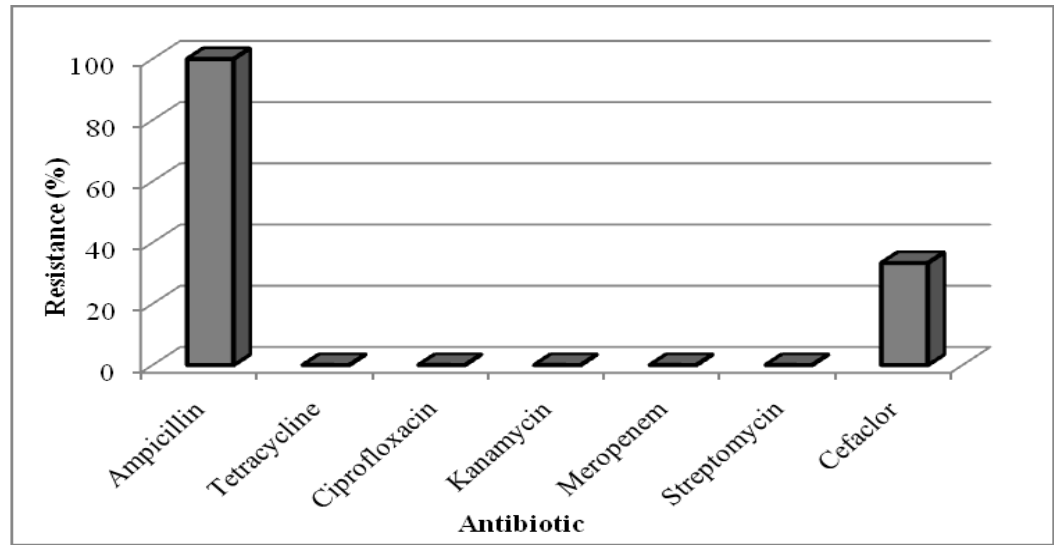

Figure 1. Antibiotic Resistance Profile of the $E$. coli Isolates

\section{Conclusion}

It is evident from this study that two-thirds of the vitamin B syrups are contaminated with huge load of microorganisms and unacceptable on the basis of the criteria set by USP. Furthermore, the presence of antibiotic 
resistant $E$. coli in syrups indicates that some of the pharmaceutical companies are not strictly following the rules of good manufacturing practices (GMP) and hazard analysis and critical control point (HACCP). The concerned authorities of Bangladesh must take necessary steps to ensure that the pharmaceutical companies abide by the rules of GMP and HACCP.

\section{References}

[1] Gad, G.F.M., R.A.I. Aly and M.S.E. Ashour, 2011. Microbial evaluation of some non-sterile pharmaceutical preparations commonly used in the Egyptian market. Trop. J. Pharm. Res., 10 (4): 437-445.

[2] Bender, D. A., Micronutrients: Vitamins and minerals, in Murry, R.K., D.A. Bender, K.M. Botham, P.J. Kennelly, V. W. Rodwell and P.A. Well, Harper's Illustrated Biochemistry, 28 (New York: McGraw Hill, 2009), 467-468.

[3] Armstrong, G. L., J. Hollingsworth and J.G. Morris, 1996. Emerging food borne pathogen: Escherichia coli 0157:H7 as a model of entry of a new pathogen into the food supply of the developed world. Epidemiol. Review, 18: 29-51.

[4] Franiczek, R., I. Dolna, B. Krzyanowska, K. Szufnarowski, B. Kowalska-Krochmal. and M. Zielinska, 2006 . Conjugative transfer frequency of resistance genes from ESBL-producing Enterobacteriaceae strains isolated from patients hospitalized in pediatric wards. Med. Dosw. Mikrobiol., 58 (1): 41-51.

[5] Hoq, M.M., M.B. Syeda and D.J. Gomes, 1991.Development of appropriate preservative system for liquid antacid I: bacterial contamination in antacid samples, Bangladesh J. Microbiol., 8: 5-10.

[6] Moniruzzaman, M., M. F. F. Ashrafi and Z. Mia, 2012. Qualitative and quantitative microbiological studies of antacid and paracetamol suspensions from different drugstores of Dhaka. Dhaka Univ. J. Biol. Sci., 21 (1):105-107.

[7] Hossain, M., S. Ara, and M.Z. Rahman, 2004. Quantitative examination of aerobic bacteria and fungi in locally available antacid suspension and possible contamination by specified bacteria. Pak. J. Bio. Sci., 7(11): 2014-2017.

[8] Brooks, G.F., K. C. Caroll, J. S. Butel and S. A. Morse,. Jawetz, Melnick \& Adelberg's medical microbiology (New York. The McGraw-Hill Co., 2007).

[9] Cappuccino, J. G. and N. Sherman. Microbiology a laboratory manual (USA: The Benjamin Cummings Publishing Co Inc. 1996).

[10]. Holt, J.G., N. R. Krieg, P. H. A. Sneath, J. T. Staley and S.T. Williams, Bergey's manual of determinative bacteriology (Baltimore, Maryland: Williams \& Wilkins, 1994).

[11]. Bauer, A. W., W.M. Kirby, J.C. Sherris and M. Turck, 1966. Antibiotic susceptibility testing by a standardized single disk method. Am. J. Clin. Pathol. 45 (4): 493-436.

[12] Clinical and Laboratory Standards Institute (CLSI), 2006. Performance standards for antibiotic disk susceptibility tests, approved standard. (9 $9^{\text {th }}$ ed.) CLSI document M2-A9, 26(1): 1-172.

[13] United States Pharmacopeia (USP 62), 2003. Microbiological examination of nonsterile products; tests for specified microorganisms. Pharm forum, 29 (5): 1722-1733.

[14] Mugoyela, V. and K. Mwambete, 2010. Microbial contamination of nonsterile pharmaceuticals in public hospital settings. Therapeutics and Clin. Risk Management, 6: 443-448.

[15] Shaikh D., T.A. Jamshed and R. Shaikh, 1988. Microbial contamination of pharmaceutical preperations of Pakistan. J. Pharm. Sci., 61-66.

[16] Aly, M.E.A., T.M. Essan and M.A. Amin, 2012. Antibiotic resistance profile of E. coli isolated from clinical specimens and food samples in Egypt. Intl. J. Microbiol. Res. 3 (3):176-182.

[17] Kamruzzaman, M., S. Shoma, S.M. Bari, A.N. Ginn, A.M. Wiklendt, S.R. Partridge, S.M. Faruque and J.R. Iredell, 2013.Genetic diversity and antibiotic resistance in Escherichia coli from environmental surface water in Dhaka City, Bangladesh. Diagnos. Microbiol. Infect. Dis., 76 (2): 222-226.

[18] Adnan, N., M. Sultana, O.K.islam, S.P. Nandi and, M.A. Hossain, 2013. Characterization of Ciprofloxacin resistant Extended Spectrum $\beta$-Lactamase (ESBL) producing Escherichia spp. from clinical waste water in Bangladesh. Adv. Biosci. Biotech., 4:15-23.

[19] Talukdar, P.K., M. Rahman, M. Rahman, A. Nabi, Z. Islam, M. M. Hoque, H. P. Endtz, M. A. Islam, 2013. Antimicrobial resistance, virulence factors and genetic diversity of Escherichia coli isolates from household water supply in Dhaka, Bangladesh. PLoS ONE, 8(4): e61090. doi:10.1371/journal.pone.0061090 